\title{
Revamping Shakespeare: Filmic Adaptation of Romeo and Juliet into Goliyon ki Rasleela Ram-Leela
}

\section{Dr. Neenu Kumar}

Associate Professor, Department of English, Aditi Mahavidyalaya, University of Delhi, India. Mail Id: neenu@aditi.du.ac.in | ORCID ID: 0000-0002-4619-9292

\begin{abstract}
Sanjay Leela Bhansali gives a regional flavour to Shakespeare's Romeo and Juliet by placing it in Gujarat. He looks at it from a local perspective. There are, however, many subtexts in Bhansali's movie: importance given to festivals, mythologizing the original text, depiction of women and their oppression at the hands of the patriarchal society. Widows presented in the movie do not find any counterparts in the Shakespearean play. Then, there are women who have minds of their own and resist: Dhankor Baa reminds the audience of Lady Capulet while parallels can be drawn between Leela and Juliet. Some women show 'signs of agency' at the end of the 'adaptation.' Local politics and national tensions make their way into Ram-Leela, clearly indicating that the movie is not merely an 'adaptation' but also a 'masala Bollywood film,' with its share of song and dance sequences, item number, 'violent skirmishes' between the two clans and the plotting to kill innocent people under the aegis of enmity. This makes it a unique combination. Ram-Leela gives a peep into modern India with its share of uncertainties, complications and the entangled weave of hatreds, jealousies and misunderstandings.
\end{abstract}

The present paper looks at Ram-Leela as a modern day adaptation of Romeo and Juliet in the Indian context.

Keywords: Race, Valour, Fate, Social Construct, Inter-Personal Conflicts

\section{Introduction:}

At the time when Shakespeare was writing and the plays were being performed at the Globe theatre, no one could have imagined the wide-ranging appeal of the local writing and performances. So much so, that the playwright's works would become 'glocal.' Shakespeare was introduced by the colonials to the colonized during their occupation of India. His plays "actively entered this colonialist process as part of the Empire's cultural and political investment" (Kapadia 1997; Sultana 2014). Those, who wanted to appear educated and rise, read and performed the plays 
with great alacrity. "Indian Empire or no Indian Empire, we cannot do without Shakespeare! Indian empire will go, at any rate, some day; but this Shakespeare does not go, he lasts forever with us" (Carlyle 1840). To the extent, same sentiments were echoed by Viswanathan: "We certainly cannot give up our Shakespeare" (Viswanathan 1986). Herein lies the 'versatility' of Shakespeare. He has not remained just British. He has become 'our Shakespeare.' Jeffrey R. Wilson writes: "Shakespeare is not universal, but Shakespeare is versatile. That is, Shakespeare is not good and true for all people in all places in all times, but his drama does have a tendency, much more than other writers from his age or others, to speak to diverse cultures in different times." 1 Hence every culture considers him to be their own. This is acculturation or "cultural translation" (Trivedi 2021).

The Bard has been translated into various languages across the globe; German, Japanese, Tamil, Marathi, Bengali and Malayalam but "strangely, no translation of his complete works exists in Hindi. [During colonialism], the English educated elite translated Shakespeare to bring him to the lesser educated commoners of India" (Trivedi 2021). In the post postcolonial era, Shakespeare's plays have been 'translated' and 'adapted' in Parsi, Bengali, Marathi and Hindi theatre and films. This is because Shakespeare "has ... always had an audience" (Hindle 2007) in "different cultures, in different times, and under different circumstances" (Trivedi 2005). The advent of globalization has made Shakespeare global, thus, having "universal validity [and] universal value" (Sultana 2014). Huang says: "... the contradiction lying in the assertions made by ... critics is that Shakespeare's canon is believed to have gone global because it is universal, but, at the same time, it is universal because it has gone global: [and the concept of] global Shakespeare itself is seen as evidence of this universality" (Huang 2016). The reason behind this is that the 'magic pages' of Shakespeare have always drawn the readers as they hold romantic, situational, mysterious, familial, conniving, or sycophantic words of the characters he presents in them.

Ever since Shakespeare was introduced to Indian readers/ audience, his works have been appropriated in Hindi cinema “... with melodramatic plots...stock characters, music and dancing" (Paromita Chakravarti cited in Thakur 2014: 22). Julie Sanders makes a fascinating contrast between 'appropriation' and 'adaptation.' She points out: "[while an adaptation] signals a relationship with an informing source-text or original, an appropriation has a more decisive journey away from the informing source-text into a totally new cultural product and domain" (Sanders 2006: 26). A filmic transference of Shakespeare can, thus, be called “an 'adaptation,' a 'transcreation,' a 'translation,' an 'interpretation,' a 'contemporisation' or even 'appropriation' or a 're-localisation in terms of language, culture, geography.' The plethora of Indian films, be it in Hindi, Bengali, or any other regional languages prove that they are all of these and some more because they add to the Bard's creations in their own way" (Chatterji 2018).

The British left years ago but the sun has not set on “Shakespeare's Empire" (Loomba 2005: 121). He continues to fascinate the Indian film directors, who have assimilated his works in the cultural, local milieu to appeal to the masses. Namrata Joshi says: “Shakespeare's plays with their dramatic

${ }^{1}$ https://wilson.fas.harvard.edu/aphorisms/shakespeare 
strength and superb portrayal of the universal truths of human nature, have always lent themselves well to adaptation to different times and places" (Mohsin 2015). Works from literature have always fascinated movie makers. The many 'adaptations' are testimony to that. Directors have constantly been engaged with the works of the playwright and "detached from the colonial baggage, [the Bard] continues to speak in strange and wondrous forms to newer generations" (Trivedi 2021). As a result, Shakespeare is very much a part of the Indian ethos even today.

Through the years, film makers constantly raided 'bookshelves' to pick up Shakespeare and read and assimilate his works. Romeo and Juliet was an epitome of a love story and has/ had always appealed to one all. Arundhati Roy writes: "The great stories are the ones you have heard and want to hear again" (Roy 2002: 229) and Romeo and Juliet was one such story. Through the years it has been 'adapted' into films by different directors: 'Anjuman (1948); Ek Duje ke Liye (1981); Qayamat se Qayamat Tak (1988); Ishaqzade (2012); Issaq and Goliyon ki Rasleela Ram-Leela (2013).

The latest (yet not-so-latest/recent) 'adaptation' of Romeo and Juliet by Bhansali is an 'Indianized' version of the original. The 'Indianization' is important as the audience has to understand the credo behind the production and the meaning/s the movie tries to communicate. The Indian filmocultural space is entirely different from that of the West. For the viewer to relate to a particular subject, in this case Romeo and Juliet, the subject-line has to be in accordance with Indian essence. The 'adaptation' has to be quintessentially Indian for the audience not only to connect to it but also to relax and enjoy it at their leisure.

Goliyon ki Rasleela Ram-Leela is a filmic depiction of unrequited love. It merely confirms that age-old rivalries cannot be overcome without sacrificing lives. Set in Gujarat, Ram-Leela, as it is popularly referred to, begins with some five hundred year old enmity between the two clans of Rajadi and Sanera, à la the Capulet and Montague family, animosity. The initial half engages the audience, as it moves at a fast pace. The colourful costumes; the song and dance sequences, the 'havelis,' the 'chandeliers' (a continuum from another Bhansali movie Hum Dil de Chuke Sanam) interspersed with the matriarch, Dhankor Baa's aka Lady Capulet's (Supriya Pathak Kapur) shouting and admonitions; the brazen display of erotic gestures by Ram aka Romeo (Ranveer Singh) and Leela $a k a$ Juliet (Deepika Padukone); occasional dialogues in rhyme; the wielding of guns in streets as an open display of competition between the warring families with the misplaced sense of bravado; and the clashes between them, keep the audience riveted to the screen. Bhansali tries "to relocate the story of [Romeo and Juliet] within an entirely human paradigm. [He attempts to present] a complex interplay of human emotions [which] results in grave crisis" (Chatterji 2018).

Into the second half and Bhansali decides to deviate from the original as the realization dawns that he cannot relegate the antagonism between the two families to the background. Ram and Leela marry but Ram is betrayed by his friends before the two can consummate their marriage. With each taken back forcibly to the respective family, attempts are afoot to marry off Leela to an NRI. Dhankor Baa cuts off Leela's ring finger when she learns of Leela's abiding love for Ram, who cuts off his own to prove his love. Rasila (widow of Kanji aka Tybalt, played by Sharad Kelkar) aka nurse 
(Richa Chaddha) is raped by Ram's friends when she is sent to the Rajadi house to give Ram the final warning to take Leela away. The rape of Rasila is unfortunate, considering that it is not performed by the members of the Rajadi family. It is used as a dramatic prop to highlight the rivalry among the two families. Baa has to avenge it because in the Sanera family the men accede to the matriarch and her strict handling of the criminal gun trade. She sends Bhavani aka Paris (Gulshan Devaiah) with his men to rape Kesar (Barka Sengupta), Meghji Bhai's - Ram's elder brother - (Abhimanyu Singh) aka Mercutio's widow. Kesar is able to escape. Ram meets Baa for peace, who agrees with the idea of killing him. Bhavani shoots Baa; blames the Rajadis; Leela becomes the head; Ram and Leela agree on the division of routes for gun trade; Bhavani tricks Leela into signing the death warrants of the Rajadis; Ram and Leela decide to shoot each other to bring peace; and Baa, after coming to know about Bhavani's nefarious designs, shoots him to bring the two families together.

It is clear that Shakespeare is 'adapted' and 'appropriated' to suit a scenario of Northern India complete with the socially generated twists of hunger for power. The lines between the supremacy of clans are drawn out clearly with the wielding of guns and their use. Margaret Jane Kidnie writes: "Cultural, geographical or ideological differences between work and adaptation are rooted in a perceived temporal gap between work and adaptation enabled by an idea of the work not as process, but as something readily identifiable instead of as an object" (Margaret 2009). Certain creative licenses are taken when a text/ play is 'adapted' into a movie. Not every director can match the opulence of Bhansali, who brings a veritable visual treat on the screen. This is one of the reasons why the picture enticed the viewers. Goliyon ki Rasleela Ram-Leela did not remain a mere 'reproduction' of Romeo and Juliet. It did try to adhere to the original in the sense of love between two young people, the intrigues and the subsequent deaths of both. However, as the man at the helm of the movie, Bhansali took "imaginative leaps in the story-telling...ensuring the viewers remain[ed] hooked to the visual spectacle as well as ... the script" (Najib 2018).

There is a symbiotic and durable relationship between the written and the visual presented on screen. The reason for this is that cinema cannot exist without literature, which has sustained it for years. One needs the other to flourish. "The publishing and film industries... have had very close relationships for decades because of adaptations" (Anish Chandy, Labyrinth Literary Agency founder quoted in Najib 2018). Both are equally engrossing media, which affect human thinking and consequent behaviour. The two are inseparable and 'adaptations' have resulted in many-a rewarding movies. Present generation has always drawn material from the literature of the previous generation. The 'range of the literature, culture, languages, theologies and philosophies' of the past is abundant. It helps the modern day film maker/ screenplay writer draw creative ideas from its well. Haroun asks Rashid Khalifa, his story-telling father:

“... where do they [the stories] come from really?"

"From the great Story Sea ... I drink the warm Story Waters and then I feel full of steam." 
"Where do you keep the hot water, then?"

"It comes out of an invisible Tap installed by one of the Water Genies ... You have to be a subscriber."

"... now kindly desist from this Iffing and Butting and be happy with the stories you enjoy." (Rushdie, 2005).

This is the 'magic realism' of Rushdie. Every film maker has to dab into this 'fertile soil' of creativity to create believable films out of the richness of the Shakespearean plays as 'adapting' Shakespeare's works for Indian films was/ is not easy. The 'realism' would die if the creative artist does not have a 'Water Genie,' and is not 'a subscriber' to the 'great Story Sea.' The transition between the scenes, portrayal of emotions, stage directions and the role given to each character, have to be captured with great fervour so that the 'adapted' work does justice to the original.

"In [plays] a lot of character development and ... space is taken up by the internal conversations and thought processes of the characters. You can't show these processes on screen, so you'll have to think around that when writing a film ... You also can't replicate the specific ways in which [drama] plays with time and memory, because everything in the script is in the present tense" (Malayalam author M. Mukundan quoted in Najib 2018). Pithy writing becomes the need of the hour. Kabir Khan feels that the screenplay is the most important aspect of film-making. The script decodes the play/ book into a good/ bad film. He says: "First, there's the brevity problem, of compressing 1,000 pages of a book into 120 pages of a script. How do you adapt it for a new audience and medium without losing the essence of the original? This is a skill-set we just don't have enough of"(Kabir Khan, Director, quoted in Najib 2018). To overcome this, many directors use/d their, and that of the screenplay writers, creativity to assimilate the local flavours so that the end result could grip the audience, amuse and captivate them and allow them to leave the theatre with a pleasant taste of having watched a worthwhile 'adaptation' of the work of an extremely wellknown dramatist because "the Indian cinema-viewing audience is, by far, the most diverse in the world, so it is really difficult to make that pan-Indian commercially successful film" (Kabir Khan quoted in Najib 2018). And, Bhansali was able to reach this end, to a certain extent.

Jonathan Gil Harris says: "It is easy to see Shakespeare as simply one of the legacies of British colonialism in India. But his popularity in Hindi cinema is not just the culmination of Thomas Macaulay's Minutes on Indian Education (Harris 1835), in which the colonial official infamously declared that 'a single shelf of a good European library [is] worth the whole native literature of India and Arabia.' It also has a lot to do with profound resonances between Shakespeare's craft and Indian cultural forms that converge on one concept: masala" (Harris 2016). This 'masala' can be found in abundance in Shakespeare. There is comedy and tragedy; romance and separation; intrigues and murders; trickery and simplicity; honesty and debauchery; adultery and betrayal; suspicion and friendship; devotion to the family; and every conceivable human emotion which has 
drawn Indian directors to tell his stories suited to the diversified social milieus in all their different embodiments. "What however, can easily place Shakespeare in [the] Indian celluloid versions is the unique 'Indianness' they are vested with by the markers, the script and the relocation of the characters, their relationships and events [which] create a distinct pattern of a definite genre in cinema distanced from other genres" (Chatterji 2018).

In adherence to the masala aspect of Ram-Leela, an item number, performed by Priyanka Chopra Jonas, is added in the movie.

Ram chahe Leela, Leela chahe Ram

In donon ke love mein duniya ka kya kaam

Inka to phanda hai simple sa yaar

Goli maaro to panga

Aankh maaro to pyaar. (Goliyon ki Rasleela Ram-Leela - lyricists - Siddharth/ Garima)

(Ram loves Leela, Leela loves Ram

In the love of the two, there is no space for the world

Their plan/agency is simple friend

Shoot a bullet and fight

Wink and it is love)

The lyrics hold true for the love Ram and Leela feel for each other as also for the local scene prevailing in the Sanera- Rajadi clans. Love makes an entry only after Ram sets eyes on Leela and Leela on Ram and the two die to bring the families together. Prior to that there had only been goliyaan (bullets) and hatred.

"You tend to read a [play] for the quality of its [dialogues]. Unfortunately, language [especially that of Shakespeare] ... is not the granite spine on which you can think of filming adaptations. That has to do with the trajectory the narrative is taking, how it sucks you in. It has to have a compelling storyline and interesting subject matter ... [An adaptation can be good in] its fidelity to the ... [play only with entertaining scenes and razor-sharp dialogues]" (Ambarish Satwik, author columnist quoted in Najib 2018). The 'adaptations' of Shakespeare cannot remain 'Shakespearesque' if they have to succeed in the Indian context. This is the reason behind adding regional character to allow them to appeal to the viewers.

There are obvious hiccups in Ram-Leela and the pace also suffers at places but despite these 'caveats,' the movie is 'adapted' well to the locales of Gujarat and is a visual treat for its costumes, chemistry, cinematography and choreography. There is a surfeit of hotness; sensory, visual and audio delight in Ram-Leela if one is so inclined and as an 'adaptation,' it does some justice to the original in the backdrop of a Gujarat village. The 'movement' and 'placement' of the camera, the 'framing,' 'visual tricks' (there is a riot of colours in the movie), 'sound design' and the 'music' are the 'tools' of a director and Bhansali uses them with aplomb. They prove to be a boon for the movie. 
Ultimately, it is the viewers who decide the fate of a movie. The screen writer can dabble with the original and change it according to the present day scenario but an amalgamation of both literature and movie is required to come up with a diversified yet 'original' account. Any limitations, which exasperate the viewers and force them to grumble that the play read better, have, then, to be looked into, improved upon and have them say 'maybe not, after all.'

The viewers are free to ask: "What's the use of stories that aren't even true? (Rushdie 2005). So, the onus lies on the script writer and the director to become an "Ocean of Notions ... the Shah of Blah" (Rushdie 2005) and bring the fictional characters and situations of the Shakespearean plays to life for a far reaching appeal to the common masses. The principles to be followed are: "find a play ... connect with the material, [find] location, location, location ... [edit] macro and micro, [put] the 'moves' in the movie,' use your source material's pedigree, use their experience to your benefit, don't call it 'opening up' [and] don't apologize for your source material" (Mirvish 2013) to make the 'transition' so smooth that the audience do not realize that they are watching an 'adaptation.'

\section{Conclusion:}

Nothing can be more irksome than a "too-faithful adaptation [or] the one that strays too far from [the] source" (Mirvish 2013). The original will always have a fan following and the likelihood of estranging them will lurk around the corners at all times. So, the audience should not be kept in suspense. The 'adaptation' has a purpose behind it. The screenplay writer and the director have to use their rationalities to 'adapt' the play as it most suits the target audience and considering that it is a Shakespearean play, which was a bona fide text and had immense cogency, the viewers are looking for something different, something new and something of an 'original adaptation.' After all, the ball is in the court of the audience once the movie is released and they do not want to watch a sloppy 'adaptation' for which they would rather not have paid and Sanjay Leela Bhansali, to his credit, is able to present a 'cinematographic adaptation' which keeps the audience glued to the screen till the last scene for the emotional investment they have made in the movie.

\section{References}

Bansali, Sanjay Leela. Goliyon Ki Rasleela Ram-Leela. Bollywood: https://www.mxplayer.in/movie/watchgoliyon-ki-rasleela-ramleela-movie-online44b5a19d79faaf10654293a1c642220d?watch=true\%20and\%20https://www.mxplayer.in/movie/watchgoliyon-ki-rasleela-ramleela-movie-online-44b5a19d79faaf10654293a1c642220d?utm_source=paid-ext-conperf-google_sem-web\&utm_medium=web\&utm_campaign=sem-web-250121-traffic-DSA-movies-mixmix-hindi-ext_paid-na-na-pan-na-nagroupm\&utm_cid=125535978868\&gclid=CjwKCAjwz_WGBhA1EiwAUAxIcV1XY7Laf1bcHr6Po6dbrwM UtUlkEo4WrdcfgMbkMtxtynyPfN6VShoC3nUQAvD_BwE, 2013. film.

Bansali, Sanjay Leela. Hum Dil De Chuke Sanam. Bollywood: https://youtu.be/mSZ7oh4OpYM, 1999. DVD. Carlyle, Thomas. Heroes And Hero Worship. 2008. Lecture III. 
Chatterji, Shoma A. "The Image Of Shakespeare In Indian Cinema." Indian Cultural Forum. N.p., 2021. Web. 26 Mar. 2021 . <https://indianculturalforum.in/2018/06/03/the-image-of-shakespeare-in-indiancinema/>.

Dionne, Craig, and Parmita Kapadia. Bollywood's Shakespeare. Newark: Palgrave Macmillan, 2014. Print.

Harris, Jonathan Gil. "The Bard in Bollywood." The Hindu. April 23, 2016. Print.

Hindle, Maurice. Studying Shakespeare on Film. Houndmills: Palgrave Macmillan, 2007. Print.

Huang, Alexa. “Global Shakespeare as a Tautalogical myth.” Scripta Uniandrade, 2016. 14:2. pp 1-7. Print.

Kapadia, Parmita. "Bastardizing The Bard: Appropriations of Shakespeare'S Plays in Post-Colonial India." Ph.D. Amherst: University of Massachusetts, 1997. Print.

Kidnie, Margaret Jane. Shakespeare and the Problem of Adaptation. New York: Routledge Publication, 2009. Print.

Loomba, Ania. "Shakespeare and the Possibilities of Postcolonial Performance." A Companion to Shakespeare and Performance. Eds. B. Hodgdon \& W. B. Worthen. Malden: Blackwell Publishing, 2005. pp 121-137. Print.

Mirvish, Dan et al. "Adapt Or Die: 13 Steps To Adapting A Film From Something Else | Filmmaker Magazine." Filmmaker Magazine | Publication with a focus on independent film, offering articles, links, and resources.. N.p., 2013. Web. 3 Mar. 2021 . <https:/ filmmakermagazine.com/76583-adapt-or-die-13-stepsto-adapting-a-film-from-something-else/\#.YOBIlegzbIU>.

Mohsin, Syed Wahaj \& Taskeen Shaista. "Cinematizing Shakespeare: A Study of Shakespearean Presence in Indian Cinema." An International Journal of English Language, Literature and Humanities, 2015. 2:10. pp 308315. Print.

Najib, Rihan, and Gold Silver. "Books, Camera, Action!." BusinessLine. N.p., 2018. Web. 16 Feb. 2021. <https://www.thehindubusinessline.com/blink/cover/books-camera-action/article24891109.ece>.

Roy, Arundhati. The God of Small Things. India: Penguin Books, 2002. Print.

Rushdie, Salman. Haroun and the Sea of Stories in Fluency in English. Eds. Promodini Varma, Mukti Sanyal, Tullika Prasad. New Delhi: Macmillan India Ltd, 2005. 12-20. Print.

Sanders, Julie. Adaptation and Appropriation. London: Routledge, 2006. Print.

Sultana, Parvin. "Indigenising Shakespeare: A Study Of Maqbool And Omkara." Academia.edu. N.p., 2014. Web. 13 May 2021.

<https://www.academia.edu/10153809/Indigenising_Shakespeare_A_study_of_Maqbool_and_Omkara $>$.

Trivedi, Poonam, and Dennis Bartholomeusz. India's Shakespeare: Translation, Interpretation And Performance. Noida: PEARSON INDIA, 2005. Print.

Trivedi, Poonam. "Shakespeare And India." OUPblog. N.p., 2016. Web. 26 Apr. 2021. <https://blog.oup.com/2016/03/shakespeare-and-india/>.

Viswanathan. "Shakespeare'S Plays And An Indian Sensibility: A Possible Sense Of Community." Images Of Shakespeare: Proceedings Of The Third Congress Of The International Shakespeare Association. W. Habitch, D. J. Palmer and R. Pringle. 1st ed. Newark: University of Delaware Press, 1986. 269-275. Print. 
Wilson, R. Jeffrey. "Aphorisms On Shakespeare." Wilson.fas.harvard.edu. N.p., 2021. Web. 11 Feb. 2021. <https://wilson.fas.harvard.edu/aphorisms/shakespeare>.

Dr. Neenu Kumar is Assoc. Prof. in English at Aditi Mahavidyalaya, University of Delhi. She is the recipient of: Best Teacher Award for academic year 2014-2015 conferred by D. H. E., N. C. T. of Delhi, awarded to a meritorious teacher from a college of University of Delhi; Certificate of Honour by Aditi Mahavidyalaya for College-Lecturer Award-2015 for outstanding academic achievements in 2017; Ecologist and Environmental Health Educationist Award; Social Worker and Nutrition Educationist Award and Environment Awareness and Promoting Girl Education Award in 2017, 2018 and 2020 respectively. She has co-edited a book Prawasi Sahitya Prasang; presented several papers at International and National Conferences; published many articles in books and journals. She is also a creative writer and has published many poems in books. 